\title{
Effect of Tobacco Cultivation on Soil Fertility and Farmer's Profitability in the Socio-Economic Perspective of Bangladesh
}

Jagadish Chandra Joardar ( $\sim$ jcjoardar@swe.ku.ac.bd)

Khulna University https://orcid.org/0000-0003-0768-7637

Kaniz Fathema

Khulna University

Sudipa Basu

University of Barisal

\section{Research Article}

Keywords: tobacco farming, soil productivity, macronutrients, soil nutrient index, farmers, costeffectiveness

Posted Date: February 28th, 2022

DOI: https://doi.org/10.21203/rs.3.rs-1388464/v1

License: (c) (i) This work is licensed under a Creative Commons Attribution 4.0 International License. Read Full License 


\section{Abstract}

Tobacco cultivation and production in Bangladesh have expanded by $99.68 \%$ and $219.4 \%$, respectively, over the last decade. The study aimed to assess the impact of tobacco cultivation on soil fertility and to compare the soil fertility status of tobacco-based (TB) and non-tobacco-based (NTB) cropping fields. The study also compared the tobacco production cost and the financial cost-effectiveness of ranchers' land utilized for tobacco farming. The researchers used soil nutrient index (SNI) to analyze the soil fertility level of TB and NTB cropping fields. A total of 40 soil samples (20 TB and 20 NTB) were collected randomly from farmers' fields in Mirpur Upazila of Bangladesh's Kushtia district. Socio-demographic and financial data from 50 tobacco ranchers were collected from the investigation territory via a wellstructured questionnaire. Soil nitrogen, phosphorus, sulfur, calcium and magnesium levels in TB fields were significantly lower than in NTB fields. Soil organic matter and $\mathrm{pH}$ in TB fields are substantially higher than in NTB fields. There was no substantial change in electrical conductivity or potassium. Based on the SNI results, the soil fertility in both cases was rated as medium. The average total cost of production for tobacco cultivation was 122190 BDT per acre of land. The average yield, all-in income, and net income per acre of land were 1292kg, 172851 BDT, and 50661 BDT, respectively, with a benefit-cost proportion of 1.42. Tobacco growers may benefit from reviewing the study's findings in making informed decisions on fertilizer applications for crops other than tobacco.

\section{Introduction}

Tobacco farming is expanding very quickly in Bangladesh where tobacco cultivation and production has increased by $99.68 \%$ and $219.4 \%$, respectively over the last 10 years (BBS 2016, 2020). The development territory extends to 26 out of 64 districts in Bangladesh and Kushtia district positions first in tobacco cultivation followed by Lalmonirhat and Nilphamari (BBS 2020).

Tobacco cultivation triggers critical unfortunate results on the surrounding environment alongside causing health hazards for tobacco farmers. Tobacco cultivating prompts consumption of soil fertility (Lecours et al. 2012), deforestation and ecological interruptions (Pius 2010; Ali et al. 2015; WHO 2017; Rahman et al. 2019). Exhaustion of soil nutrients is likely a result of the more huge info prerequisite to the tobacco crop (Hoyos et al. 2015). The tobacco plant consumes a large amount of soil nutrients and exhausts them at a faster rate than most other crops. The lingering fertilizer treatments have little effect on succeeding food harvests (Geist 2018). To achieve high leaf output and quality, the tobacco plant requires more nutrients, such as nitrogen $(N)$, phosphorous $(P)$, potassium $(K)$, calcium $(C a)$, magnesium (Mg), and sulfur (S) (Ali et al. 2015). Researchers have reported a decrease in soil supplements such as K, P, and S (Xu et al. 2008; Farooq et al. 2014; Moula et al. 2018; Lisuma et al. 2020) as well as an increase in total soil-N and Ca content following tobacco growing (López-Lefebre et al. 2001; Farooq et al. 2014; Lisuma et al. 2020).

Soil analysis evaluates the existing fertility status and gives data in regards to nutrient accessibility in soils, which frames the reason for sustainable soil and fertilizer management to expand crop yields and 
support ideal soil health. For reasonable soil management, the rancher should understand what corrections are needed to advance the productivity of the soil (Kavitha and Sujatha 2015). An appraisal of the soil fertility status by utilizing a soil nutrient index could give key data to improve procedures and successful strategies for the future to accomplish sustainable agriculture.

The tobacco companies generally assert that tobacco farming creates productive work open doors and revenue for tobacco farmers yet this sector has debate. Nevertheless, throughout the time and among the various crops cultivated in Bangladesh, tobacco is playing a continuously significant role in creating work and pay possibilities for farmers and furthermore supporting in accepting imperative foreign cash for the country. Despite the fact that tobacco farming has been viewed as moneymaking by a few, the gatherings against tobacco cultivation allies considers it as a crop which is irksome, socially, monetarily and ecologically. Investigations in various tobacco-cultivating nations have analyzed the monetary occupations of tobacco farmers (Appau et al. 2019; Hasan 2019; Rahman et al. 2019; Rahman et al. 2019), the components that shape farmers' choices to cultivate tobacco, and financial options in contrast to tobacco production.

This investigation centers around the evaluation of the impact of tobacco farming on soil fertility status utilizing soil nutrient index approach and comparison of tobacco based (TB) with non-tobacco based (NTB) cropping pattern field. Additionally, the study emphasizes the influences of tobacco cultivation on the farmers' socio-economic conditions and the cost-effectiveness of tobacco production in the study area.

\section{Materials And Methods}

\subsection{Study Area}

Kushtia district of Bangladesh was picked purposively as the investigation territory since this locale positions first in tobacco cultivation in Bangladesh (BBS 2020). The study comprised of two sections (i) soil sample was collected from both TB and NTB cultivating fields to assess the fertility status of the soil, and (ii) a well-structured questionnaire survey was directed to discover the farmer's profitability in the study territory because of tobacco cultivation.

\subsection{Soil Sampling and Analysis}

The fields were chosen arbitrarily by finding out if the farmers cultivate tobacco or not. Soil samples were taken at $0-15 \mathrm{~cm}$ depth from 9 places in each field, mixed systematically to form a composite soil sample for each TB and NTB cultivating field independently, and a total of 40 fields (20 TB, 20 NTB) were chosen. The soils were air-dried, visible roots and garbage were removed, and the larger aggregates were delicately crushed with a wooden hammer before being put through a $0.5-\mathrm{mm}$ sieve. Approximately 0.5 $\mathrm{kg}$ of composite soil samples were placed in fresh polythene sacks, labeled, and stored for analysis. A glass electrode $\mathrm{pH} / \mathrm{EC}$ meter was used to determine the $\mathrm{pH}$ and $\mathrm{EC}$ of the soil (D-54, Horiba, Japan) (Jackson 1958). Walkley and Black's wet oxidation method (Walkley and Black 1934) was used to 
quantify soil organic carbon (OC), and the $\mathrm{OM}$ was estimated by multiplying the percent value of $\mathrm{OC}$ by the traditional Van-Bemmelene's factor of 1.724. Total $\mathrm{N}$ of soil was assessed by the Micro-Kjeldahl technique (Jackson 1958), available soil $P$ and $S$ was estimated by using a spectrophotometer (T60U, UVapparent spectrophotometer, PG Instruments Ltd) (Page et al. 1982; Olsen 1954), exchangeable K was determined by using flame photometer (PFP7 Flame Photometer, JENWAY) (Jackson 1958). Available Ca and $\mathrm{Mg}$ were determined by titrimetric method (Imamul Huq and Alam 2005).

\subsection{Valuation of Soil Fertility Status through Soil Nutrient Index (SNI)}

Soil fertility, or the amount of plant nutrients in the soil, is mostly determined by soil quality and health. It is critical to obtain a single number for each nutrient when comparing the degrees of soil fertility of one region to those of another. The SNI value is a measurement of the soil's ability to give nutrients to plants (Singh et al. 2016). A few scientists have updated and enhanced the SNI technique given by Parker et al. (Parker et al. 1951; Shetty et al. 2008; Pathak 2010; Chase and Singh 2014; Amara et al. 2017; Patil et al. 2017). This index is used to determine the fertility status of soils based on samples from each of the three classes: low, medium, and high fertility. The SNI was assessed for the soil samples studied using the following formula:

Nutrient Index $(\mathrm{NI})=(\mathrm{NI} * 1+\mathrm{Nm} * 2+\mathrm{Nh} * 3) / \mathrm{Nt}$

Where,

$\mathrm{NI}, \mathrm{Nm}$, and $\mathrm{Nh}$ denote the number of tests in the low, medium, and high nutritional status categories, respectively. Nt denotes the total number of tests performed on a given region.

\subsection{Survey Design and Data Collection}

A random sampling technique was applied for picking sample and 50 ranchers were chosen for the study. Essential information was gathered with care and alert through face-to-face interviews with the respondents. Preceding meeting, the goals of the examination were disclosed to every single tobacco farmers. Subsequently, they were persuaded that the examination was absolutely a scholastic one and was not prone to adversely affect their cultivating.

\subsection{Data Analysis Techniques}

To examine profitability and production proficiency in tobacco production in the inquiry territory, a benefitcost analysis (BCA) and a Cobb-Douglas production model were used.

\subsubsection{Farmers' Profitability of Tobacco Farming}

To estimate the expense and get back from tobacco farming, accessible information on cost and return made by tobacco farmers was utilized to compute with exactness. Family-level data on socioeconomics, financial profiles of respondents, and information associated with tobacco cultivation, such as land, 
labor, fertilizer, pesticides, other factor costs, loan facility, and other tobacco handling-related data, tobacco cost, and profitability of tobacco cultivation, were gathered. The farmers' financial gain was calculated by subtracting the sales revenue of tobacco from the costs of all out-of-pocket inputs utilized in tobacco growing.

\subsubsection{Benefit-Cost Analysis}

In assessing the expense viability of tobacco cultivation, the study employed BCA procedure referenced below (Haider 2015; Jahan and Islam 2016; Basu and Roy 2018).

$$
\mathrm{BC}=\frac{\text { DirectBenefit }(\mathrm{DB})}{\operatorname{DirectCost}(\mathrm{DC})}=\frac{\sum_{\mathrm{i}-1}^{\mathrm{n}} \mathrm{DB}_{\mathrm{i}}}{\sum_{\mathrm{k}-1}^{\mathrm{n}} \mathrm{DC}_{\mathrm{k}}}(1)
$$

Here, $B C=$ benefit-cost ratio; $D B=$ direct benefit; $D C=$ direct cost; $n=1$ for $D C$ (production cost); $n=1$ for DB (revenue earnings)

\subsubsection{Production Function Model}

To evaluate the tobacco production scheme's production proficiency, the Cobb-Douglas production model in the form below was used (Ahmed and Garnett 2011).

$$
\log _{\mathrm{i}}=\log _{\mathrm{a}}+\mathrm{b}_{1} \log \mathrm{X}_{1 \mathrm{i}}+\mathrm{b}_{2} \log \mathrm{X}_{2 \mathrm{i}}+\mathrm{b}_{3} \log \mathrm{X}_{3 \mathrm{i}}+\mathrm{b}_{4} \log \mathrm{X}_{4 \mathrm{i}}+\mathrm{b}_{5} \log \mathrm{X}_{5 \mathrm{i}}+\log \mathrm{U}_{\mathrm{i}}
$$

where, $Y=$ Total yield from tobacco cultivation ( $\mathrm{kg} / \mathrm{acre}) ; \mathrm{X}_{1}=$ tobacco seedling (BDT/acre); $\mathrm{X}_{2}=$ fertilizer $(B D T / a c r e) ; X_{3}=$ pesticide $(B D T / a c r e) ; X_{4}=$ irrigation $(B D T / a c r e) ; X_{5}=$ labor $(B D T / a c r e) ; U_{i}=$ disturbance term; $a=$ constant; $b_{1} \otimes b_{4}=$ coefficient of the related variables; $i=$ observations $(1,2,3$

\subsection{Statistical Analysis}

The produced soil information was analyzed statistically by analysis of variance. Mean comparisons were performed employing an ANOVA ensured least significant difference (Tukey) $(p<0.05)$ test. Simple correlation analysis was performed between the contemplated attributes (Steel et al. 1997). Gathered information from questionnaire survey were investigated and summed up with the end goal of tabulation using the statistical software MINITAB 18 and Microsoft office Excel 2010.

\section{Results And Discussion}

\subsection{The Impact of Tobacco Farming on Soil Fertility}

The average $\mathrm{pH}$ value was $7.43 \pm 0.10$ for TB soil whereas it was $7.17 \pm 0.19$ in NTB soil. Soil in the TB field was slightly alkaline in nature and it was neutral in NTB field. Based on soil EC values both TB and NTB fields were non-saline (Table 1). The OM content of TB land varied from 1.07 to $3.03 \%$ with average of $2.18 \pm 0.50 \%$ indicating low $(10 \%)$ to medium $(90 \%)$ soil OM and the NTB soils were categorized very low (90\%) to low (10\%) (Ahmmed et al. 2018). The mean value of total soil N from TB field was $0.06 \pm$ 
$0.03 \%$, which was below the critical limit value (0.12\%) (Ahmmed et al. 2018). The $\mathrm{N}$ content in TB field was categorized as very low (85\%) to low (15\%) whereas it was categorized as low (95\%) to medium (5\%) in NTB soils (Ahmmed et al. 2018). The average P value in TB and NTB fields were $31.9 \pm 10.8$ and $47.3 \pm$ $9.88 \mathrm{mg} / \mathrm{kg}$, respectively. The $\mathrm{K}$ and $\mathrm{S}$ level of the TB soils was $0.43 \pm 0.11 \mathrm{meq} / 100 \mathrm{~g}$ and $17.8 \pm 6.80$ $\mathrm{mg} / \mathrm{kg}$, respectively, whereas in NTB soils it was $0.47 \pm 0.08 \mathrm{meq} / 100 \mathrm{~g}$ and $38.3 \pm 6.14 \mathrm{mg} / \mathrm{kg}$, respectively. The level of exchangeable $\mathrm{Ca}$ and $\mathrm{Mg}$ in TB soils was $1.64 \pm 0.83 \mathrm{meq} / 100 \mathrm{~g}$ and $1.40 \pm 0.42$ $\mathrm{meq} / 100 \mathrm{~g}$, respectively, whereas in NTB soils it was $3.58 \pm 0.69 \mathrm{meq} / 100 \mathrm{~g}$ and $2.24 \pm 0.51 \mathrm{meq} / 100 \mathrm{~g}$, respectively (Table 1 ). Similar to $\mathrm{N}$, the Ca content in TB soil was below the critical limit value (2 meq/100g) (Ahmmed et al. 2018).

Table 1

Statistic characteristics of soil variables in TB and NTB fields

\begin{tabular}{|lllllllll|}
\hline Soil variables & \multicolumn{3}{c}{ Tobacco based soil } & \multicolumn{4}{c|}{ Non-tobacco based soil } \\
\cline { 2 - 9 } & Mean & Max. & Min. & SD & Mean & Max. & Min. & SD \\
\hline pH & $7.43^{\mathrm{a}}$ & 7.71 & 7.32 & \pm 0.10 & $7.17^{\mathrm{b}}$ & 7.43 & 6.86 & \pm 0.19 \\
\hline EC (dS/m) & $0.08^{\mathrm{a}}$ & 0.09 & 0.06 & \pm 0.01 & $0.08^{\mathrm{a}}$ & 0.10 & 0.07 & \pm 0.01 \\
\hline OM (\%) & $2.18^{\mathrm{a}}$ & 3.03 & 1.07 & \pm 0.50 & $0.75^{\mathrm{b}}$ & 1.03 & 0.47 & \pm 0.14 \\
\hline Total N (\%) & $0.06^{\mathrm{b}}$ & 0.13 & 0.01 & \pm 0.03 & $0.14^{\mathrm{a}}$ & 0.19 & 0.10 & \pm 0.02 \\
\hline Av. P (mg/kg) & $31.9^{\mathrm{b}}$ & 52.2 & 16.0 & \pm 10.8 & $47.3^{\mathrm{a}}$ & 69.9 & 33.2 & \pm 9.88 \\
\hline Ex. K (meq/100g) & $0.43^{\mathrm{a}}$ & 0.71 & 0.28 & \pm 0.11 & $0.47^{\mathrm{a}}$ & 0.67 & 0.37 & \pm 0.08 \\
\hline Av. S (mg/kg) & $17.8^{\mathrm{b}}$ & 31.3 & 6.17 & \pm 6.80 & $38.3^{\mathrm{a}}$ & 50.4 & 30.1 & \pm 6.14 \\
\hline Ex. Ca (meq/100g) & $1.64^{\mathrm{b}}$ & 3.18 & 0.20 & \pm 0.83 & $3.58^{\mathrm{a}}$ & 4.98 & 2.12 & \pm 0.69 \\
\hline Ex. Mg (meq/100g) & $1.40^{\mathrm{b}}$ & 2.12 & 0.76 & \pm 0.42 & $2.24^{\mathrm{a}}$ & 3.14 & 1.36 & \pm 0.51 \\
\hline
\end{tabular}

The numbers followed by the same letter in the different column showed non-significantly different at confidence level of $5 \%$. Where, $\mathrm{EC}=$ electrical conductivity; $\mathrm{OM}=$ organic matter; $\mathrm{N}=$ nitrogen; $\mathrm{Av} . \mathrm{P}=$ available phosphorus; Ex. $\mathrm{K}=$ exchangeable potassium; $\mathrm{Av}$. $\mathrm{S}=$ available sulfur; $\mathrm{Ex}$. $\mathrm{Ca}=$ exchangeable calcium; Ex. Mg = exchangeable magnesium; Max.= maximum; Min.= minimum; $\mathrm{SD}$ = standard deviation

\subsection{Relationship among the Studied Soil Variables}

Soil pH had a significant and positive relationship with $\mathrm{OM}$, but a negative relationship with $\mathrm{N}, \mathrm{P}, \mathrm{Ca}$, and $\mathrm{Mg}$; a non-significant and positive relationship with $\mathrm{K}$, but a negative relationship with $\mathrm{EC}$. N, $\mathrm{P}, \mathrm{Ca}$, and $\mathrm{Mg}$ were favorably connected with $\mathrm{EC}$, while $\mathrm{OM}$ and $\mathrm{K}$ were adversely linked but not significantly. $\mathrm{OM}$ was shown to be strongly linked with $\mathrm{N}, \mathrm{P}, \mathrm{Ca}$, and $\mathrm{Mg}$, as well as insignificantly but negatively linked with 
K. P, K, Ca, and Mg were all significantly and positively linked with N. P was found to have a substantial and positive relationship with $\mathrm{K}, \mathrm{Ca}$, and $\mathrm{Mg} . \mathrm{K}$ had a non-significant positive correlation with $\mathrm{Ca}$ and $\mathrm{Mg}$. $\mathrm{Mg}$ and Ca had a substantial positive correlation (Table 2).

Table 2

Pearson correlation coefficient matrix among the studied soil variables

\begin{tabular}{|c|c|c|c|c|c|c|c|}
\hline $\begin{array}{l}\text { Soil } \\
\text { variables }\end{array}$ & $\mathrm{pH}$ & EC & $\mathrm{OM}$ & $\mathbf{N}$ & $P$ & $K$ & $\mathrm{Ca}$ \\
\hline \multirow[t]{2}{*}{ EC } & -0.213 & & & & & & \\
\hline & $\begin{array}{l}(p= \\
0.187)\end{array}$ & & & & & & \\
\hline \multirow[t]{2}{*}{ OM } & 0.518 & -0.177 & & & & & \\
\hline & $\begin{array}{l}(p= \\
0.001)\end{array}$ & $\begin{array}{l}(p= \\
0.275)\end{array}$ & & & & & \\
\hline \multirow[t]{2}{*}{$N$} & -0.581 & 0.087 & -0.771 & & & & \\
\hline & $\begin{array}{l}(p= \\
0.000)\end{array}$ & $\begin{array}{l}(p= \\
0.595)\end{array}$ & $\begin{array}{l}(p= \\
0.000)\end{array}$ & & & & \\
\hline \multirow[t]{2}{*}{$P$} & -0.398 & 0.016 & -0.466 & 0.594 & & & \\
\hline & $\begin{array}{l}(p= \\
0.011)\end{array}$ & $\begin{array}{l}(p= \\
0.922)\end{array}$ & $\begin{array}{l}(p= \\
0.002)\end{array}$ & $\begin{array}{l}(p= \\
0.000)\end{array}$ & & & \\
\hline \multirow[t]{2}{*}{$\mathrm{K}$} & 0.057 & -0.240 & -0.152 & 0.406 & 0.343 & & \\
\hline & $\begin{array}{l}(p= \\
0.729)\end{array}$ & $\begin{array}{l}(p= \\
0.136)\end{array}$ & $\begin{array}{l}(p= \\
0.349)\end{array}$ & $\begin{array}{l}(p= \\
0.009)\end{array}$ & $\begin{array}{l}(p= \\
0.030)\end{array}$ & & \\
\hline \multirow[t]{2}{*}{$\mathrm{Ca}$} & -0.476 & 0.053 & -0.771 & 0.608 & 0.391 & 0.042 & \\
\hline & $\begin{array}{l}(p= \\
0.002)\end{array}$ & $\begin{array}{l}(p= \\
0.747)\end{array}$ & $\begin{array}{l}(p= \\
0.000)\end{array}$ & $\begin{array}{l}(p= \\
0.000)\end{array}$ & $\begin{array}{l}(p= \\
0.013)\end{array}$ & $\begin{array}{l}(p= \\
0.796)\end{array}$ & \\
\hline \multirow[t]{2}{*}{$\mathrm{Mg}$} & -0.512 & 0.177 & -0.679 & 0.524 & 0.357 & 0.239 & 0.590 \\
\hline & $\begin{array}{l}(p= \\
0.001)\end{array}$ & $\begin{array}{l}(p= \\
0.275)\end{array}$ & $\begin{array}{l}(p= \\
0.000)\end{array}$ & $\begin{array}{l}(p= \\
0.001)\end{array}$ & $\begin{array}{l}(p= \\
0.024)\end{array}$ & $\begin{array}{l}(p= \\
0.137)\end{array}$ & $\begin{array}{l}(p= \\
0.000)\end{array}$ \\
\hline
\end{tabular}

\subsection{Valuation of Soil Fertility Status}

To compare the levels of soil fertility in one region with those in another, a single value for each nutrient is required (Amara et al. 2017). The SNI of both the TB and NTB fields was computed using soil nutrient ratings of low $(L)$, medium $(M)$, and high $(H)$. The fertility status was low if the index value was less than 1.67, medium if it was between 1.67 and 2.33, and high if it was greater than 2.33 (Parker et al. 1951; Shetty et al. 2008; Pathak 2010; Chase and Singh 2014; Amara et al. 2017; Patil et al. 2017). Based on SNI, between TB and NTB field, soil pH was high in TB soil and medium in NTB soil. In both the cases, 
soil total $\mathrm{N}$ and $\mathrm{EC}$ was low while available $\mathrm{P}$, exchangeable $\mathrm{K}$ and exchangeable $\mathrm{Mg}$ were high. The level of OM was medium in TB soil and low in NTB soil. Available $S$ fertility status was medium in TB soil and high in NTB soil. Level of exchangeable Ca was low in TB soil and medium in NTB soil (Table 3).

Table 3

Distribution of $\mathrm{SNI}$ and soil fertility rating (SFR) based on SNI

\begin{tabular}{|c|c|c|c|c|}
\hline \multirow[t]{2}{*}{ Soil variables } & \multicolumn{2}{|c|}{ Tobacco based soil } & \multicolumn{2}{|c|}{ Non-tobacco based soil } \\
\hline & SNI & SFR & SNI & SFR \\
\hline $\mathrm{pH}$ & 3.0 & $\mathrm{H}$ & 2.3 & M \\
\hline $\mathrm{EC}(\mathrm{dS} / \mathrm{m})$ & 1.0 & $\mathrm{~L}$ & 1.0 & L \\
\hline Organic matter (\%) & 1.9 & M & 1.0 & L \\
\hline Total N (\%) & 1.0 & $\mathrm{~L}$ & 1.1 & L \\
\hline Available P (mg/kg) & 2.8 & $\mathrm{H}$ & 3.0 & $\mathrm{H}$ \\
\hline Exchangeable K (meq/100g) & 3.0 & $\mathrm{H}$ & 3.0 & $\mathrm{H}$ \\
\hline Available S (mg/kg) & 1.8 & M & 3.0 & $\mathrm{H}$ \\
\hline Exchangeable $\mathrm{Ca}(\mathrm{meq} / 100 \mathrm{~g})$ & 1.1 & $\mathrm{~L}$ & 1.9 & $M$ \\
\hline Exchangeable Mg (meq/100g) & 2.7 & $\mathrm{H}$ & 3.0 & $\mathrm{H}$ \\
\hline \multicolumn{5}{|c|}{ SNI = Soil nutrient index; SFR = soil fertility rating; $L=L o w ; M=$ Medium; $H=$ High } \\
\hline
\end{tabular}

Tobacco farmers' age ranged from 27 to 59 years, with the mean of 43.2 years. Farmers were illiterate to having tertiary education but the average farmers' education level was just above seven years. Tobacco farmers' family size of the study area ranged from 3 to 10 persons, with an average household size is just above 5 persons including all members. Average cultivated land size was 2.1 acre and ranged from 1.0 to 3.7 acre (Table 4). 
Table 4

Household features, total cost and revenue profitability and benefit-cost ratio in tobacco cultivation per acre of land in the study area

\begin{tabular}{|c|c|c|c|c|c|c|}
\hline & Items & Mean & $\begin{array}{l}\text { SE } \\
\text { Mean }\end{array}$ & CoefVar & Min & Max \\
\hline \multirow{4}{*}{$\begin{array}{l}\text { Household } \\
\text { features }\end{array}$} & Age (years) & 43.2 & 1.2 & 19.3 & 27.0 & 59.0 \\
\hline & $\begin{array}{l}\text { Education (schooling } \\
\text { years) }\end{array}$ & 7.2 & 0.5 & 46.9 & 0.0 & 17.0 \\
\hline & Family size (person) & 5.1 & 0.2 & 26.9 & 3.0 & 10.0 \\
\hline & Cultivated land (acre) & 2.1 & 0.1 & 35.2 & 1.0 & 3.7 \\
\hline \multirow[t]{9}{*}{ Cost (BDT) } & Land lease & 19894 & 2933 & 104.2 & 2121 & 48030 \\
\hline & Seedling & 1318 & 161.0 & 86.2 & 0 & 2424 \\
\hline & Fertilizers & 24158 & 449.0 & 13.2 & 18182 & 30303 \\
\hline & Pesticides & 1227 & 30.7 & 17.7 & 909 & 1515 \\
\hline & Irrigation & 5891 & 103.0 & 12.4 & 3939 & 7273 \\
\hline & Leaf curing process & 29263 & 177 & 4.3 & 26727 & 32242 \\
\hline & Transport & 2552 & 40.0 & 11.1 & 1818 & 3333 \\
\hline & Total labor & 32848 & 2418.0 & 52.0 & 10606 & 53030 \\
\hline & Others & 5039 & 68.4 & 9.6 & 4136 & 5652 \\
\hline \multicolumn{2}{|l|}{ Total cost (BDT) } & 122190 & 1048.0 & 6.1 & 104576 & 133621 \\
\hline \multirow[t]{5}{*}{ Revenue (BDT) } & Tobacco by-product & 3485 & 186.0 & 37.7 & 1515 & 6061 \\
\hline & Selling dry plant & 1255 & 32.1 & 18.1 & 909 & 1818 \\
\hline & Price/kg & 130 & 0.5 & 2.5 & 125 & 135 \\
\hline & Tobacco leaf $(\mathrm{kg})$ & 1292 & 14.2 & 7.8 & 1152 & 1515 \\
\hline & Yield return & 168111 & 1946.0 & 8.2 & 147394 & 204545 \\
\hline \multicolumn{2}{|c|}{ Total revenue (BDT) } & 172851 & 1924.0 & 7.9 & 151333 & 209394 \\
\hline \multicolumn{2}{|c|}{ Net revenue (BDT) } & 50661 & 2024.0 & 28.3 & 28318 & 86076 \\
\hline \multicolumn{2}{|c|}{ Benefit-cost ratio (BCR) } & 1.42 & 0.019 & 9.21 & 1.22 & 1.81 \\
\hline
\end{tabular}


This sub-section describes total cost (TC), total revenue (TR), net revenue (NR) and benefit-cost ratio (BCR) involved in tobacco cultivation per acre of farmer's land.

Input costs

The input cost involved are land preparation, land lease, seedling, fertilizers, pesticides, irrigation, leaf curing process (house making materials, wood etc.), transport for marketing, total labor and so on. The average total cost for tobacco cultivation is 122190 BDT per acre of land ranged from 104576 to 133621 BDT (Table 4).

\section{Total revenue}

Returns heads from tobacco cultivation are tobacco leaf (yield), selling tobacco by-product, and dry plants. Average total revenue per acre of land from tobacco is 172851 BDT ranged from 151333 to 209394 BDT. Average total yield per acre of land is $1292 \mathrm{~kg}$ and ranged from 1152 to $1515 \mathrm{~kg}$. The mean yield return is 168111 BDT and ranged from 147394 to 204545 BDT from per acre of land (Table 4).

\subsubsection{Economic Profitability of Tobacco Farming}

Based on the cost and revenue data from this study, the average production cost (including all sources of cost), sales revenue of tobacco leaf and by-products, and average profit and rate of profit (profit as a proportion of cost) per acre of land were computed. Tobacco net revenue averaged 50661 BDT, ranging from $28318 \mathrm{BDT}$ to $86076 \mathrm{BDT}$. The profit margin as a percentage of the total cost of manufacturing is 41.5 percent. The average benefit-to-cost ratio is $1.42 \mathrm{BDT}$, with values ranging from 1.22 to $1.81 \mathrm{BDT}$ (Table 4).

\section{Production efficiency}

In the econometric regression model of the Cobb-Douglas production function, $\mathrm{R}^{2}$ is 0.93 , implying that the independent variables in the model can explain $93 \%$ of the variation in tobacco output. The model's Fvalue (108.38) was highly significant $(p<0.001)$, indicating that all of the descriptive variables were necessary for understanding the production system's fluctuations (Table 5). 
Table 5

Efficiency measurement of tobacco production

\begin{tabular}{|c|c|c|c|c|c|c|}
\hline Variables & Unit & Coef & SE Coef & T-Value & P-Value & VIF \\
\hline Seedling $\left(X_{1}\right)$ & (BDT/acre) & 0.2248 & 0.0609 & 3.69 & 0.001 & 4.79 \\
\hline Fertilizer $\left(X_{2}\right)$ & (BDT/acre) & 0.01813 & 0.00493 & 3.68 & 0.001 & 6.36 \\
\hline Pesticide $\left(X_{3}\right)$ & (BDT/acre) & 0.0861 & 0.0960 & 0.90 & 0.375 & 4.70 \\
\hline Irrigation $\left(X_{4}\right)$ & (BDT/acre) & 0.0472 & 0.0215 & 2.19 & 0.034 & 7.38 \\
\hline Labor $\left(X_{5}\right)$ & (BDT/acre) & -0.00141 & 0.00155 & -0.91 & 0.368 & 2.06 \\
\hline Constant & & 77 & 131 & 0.58 & 0.562 & \\
\hline$R^{2}$ & 0.93 & & & & & \\
\hline F-Value & 108.38 & & & & & \\
\hline P-Value & 0.000 & & & & & \\
\hline Observations & 50 & & & & & \\
\hline Mean VIF & 5.06 & & & & & \\
\hline
\end{tabular}

\subsection{Farmers' Opinions about Tobacco Farming}

Farming is the main occupation for majority of the farmers. The farmers' opinions are summarized as the percentage of the total respondents. $58 \%$ of the farmers grow tobacco in their own land and $66 \%$ of the respondents have taken training course on tobacco cultivation. For tobacco cultivation, $82 \%$ of the farmers are motivated by different tobacco companies and $74 \%$ of the farmers get loan from the companies. $76 \%$ of the farmers sell tobacco leaf to the company and the rest of the farmers sell to the market. Regarding health issue, $70 \%$ of the farmers think that tobacco farming is harmful for health and it was found that $50 \%$ of the tobacco growers, $38 \%$ of the family members and $32 \%$ of female members are addicted to tobacco. $72 \%$ of the farmers think tobacco cultivation pollutes the environment particularly air. $62 \%$ of the respondents told that tobacco cultivation need higher amounts of fertilizer and they apply more fertilizer than the recommended dose. Commonly used fertilizers are urea, TSP (triple super phosphate), DAP (diammonium phosphate) and SOP (sulphate of potash). Furthermore, tobacco plants attract more pests and insects, necessitating the use of additional pesticides in tobacco production. Tobacco cultivation, according to $68 \%$ of farmers, declines soil productivity since it necessitates more fertilizer for the next crop. An opposite and $90 \%$ of the respondents think that tobacco cultivation has no detrimental effect on next crop. This might be due to high application of fertilizer to the next crop. $80 \%$ of the farmers consider that the tobacco cultivation is more profitable than most other crops and $54 \%$ farmers think that they get more money at a time. 
The results indicated that the $\mathrm{pH}$ value of TB soil was significantly higher than that of NTB soil (Table 1). On considering soil $\mathrm{pH}, 25 \%$ of TB soils were within neutral range and $75 \%$ were within slightly alkaline whereas $85 \%$ of NTB soils were within neutral range and $15 \%$ were within slightly alkaline. This result is in good agreement with the findings of Salam et al. (Salam et al. 2021). However, opposite findings were also reported (Kutub and Falgunee 2017; Moula et al. 2018). Both TB and NTB soils were non-saline in nature and the entire analyzed sample's EC value was below $1.0 \mathrm{dS} / \mathrm{m}$ (Ahmmed et al. 2018). Higher EC value in NTB fields was reported (Salam et al. 2021). Based on SNI, soil OM content is medium in TB soil and low in NTB soil (Table 1). Similar result with this finding was stated (Salam et al. 2021). However, opposing finding was also reported (Moula et al. 2018). High amount of residues like root biomass left after harvest leaving more chances of OM accumulation in the TB soil. In addition, low input of organic fertilizer and crop residues thereby less chances of OM accumulation in NTB soil. It was found that the total soil N content was significantly differed from TB and NTB farming fields and it was significantly lower in TB farming fields than that of NTB farming fields (Table 1). Though, SNI value showed that the $\mathrm{SFR}$ is low for both the cases. The low $\mathrm{N}$ level could be due to poor soil management. Furthermore, the amount of $\mathrm{N}$ in the soil is affected by temperature, rainfall, and altitude. Moreover, continual and intensive cultivation, which results in significant crop removal and insufficient replenishment, may be the cause of high levels of $\mathrm{N}$ shortage in soils (Amara et al. 2017). A study on consecutive 2-year data analysis reported that soil $\mathrm{N}$ was decreased in tobacco field in the second year and the $\mathrm{N}$ content was lower in tobacco field than non-tobacco field (Salam et al. 2021). An increase in total soil-N level has also been reported after tobacco cultivation (López-Lefebre et al. 2001; Farooq et al. 2014; Lisuma et al. 2020). Findings showed that tobacco cultivation resulted a decrease in soil available $\mathrm{P}$ and $\mathrm{S}$. The $\mathrm{P}$ levels in TB cropping pattern fields were included in the category of medium (20\%), optimum (30\%), and high (50\%) whereas the category was high $(15 \%)$ to very high $(85 \%)$ for all the NTB fields (Ahmmed et al. 2018). Lesser content of available $\mathrm{P}$ and $\mathrm{S}$ was also reported in TB fields after tobacco cultivation which is supportive to this result (Moula et al. 2018; Lisuma et al. 2020; Salam et al. 2021). However, the SNI value for $P$ revealed that the SFR is high in both situations (Table 3), possibly due to the large phosphate fertilizer input throughout time. High soil P levels not only reduce the availability and uptake of vital nutrients by plants, but they also pollute the soil and water. The decline in soil $\mathrm{S}$ in tobacco fields could be attributable to the high plant demand for this nutrient for metabolic activities (Höller et al. 2010), as well as a lack of adequate $S$ input and constant $S$ removal by crops. Exchangeable $\mathrm{K}$ value of TB soils were the category of high (50\%) to very high (50\%) whereas the categories were optimum (25\%), high (35\%) and very high (40\%) in NTB soils (Ahmmed et al. 2018). There was no significant change of average $\mathrm{K}$ value in TB and NTB soils (Table 1) but significantly higher $\mathrm{K}$ value in NTB soil was stated (Salam et al. 2021). Similar to $P$, the SFR for $K$ is high for both the cases (Table 3 ).

Significant and negative correlation between soil $\mathrm{pH}$ and $\mathrm{N}$ indicated that an increase in soil $\mathrm{pH}$ decreases $\mathrm{N}$, which might be due to volatilization loss of $\mathrm{N}$ with rise of soil pH (Bhat et al. 2017). Similar results were also reported indicating significant and negative correlation between soil $\mathrm{pH}$ and $\mathrm{N}$ (Khokhar et al. 2012; Patil at al. 2015). Based on SNI value, the soil fertility was characterized as medium in both TB and NTB soils. 
The study shows that the profit relies upon so many factors some of them are cost on seedlings, fertilizer and pesticides, labor, irrigation, production, price and so on. Though tobacco cultivation has some short term momentary beneficial outcomes tobacco cultivation has some adverse consequences on soil fertility, water quality, environment, deforestation and health. Wood burning during tobacco leaves curing process discharges noxious smoke in the atmosphere. Above all, when the opportunity costs of having family labor, own property, and other resources are considered, tobacco farming is clearly not a profitable endeavor for farmers. The production of food crops has been decreasing with time because of augmentation of tobacco production. The government and others working on tobacco control should offer significant monetary help by assisting with expanding admittance to credit and guaranteeing a superior market facility to sell their other healthier agricultural harvests. To manage the tobacco pandemic in Bangladesh, these factors must be addressed, as well as incentives for tobacco farmers to switch to other sources of income. We didn't measure the environmental costs of tobacco cultivation as well as the implied costs (e.g., free family labor, health costs), which is a key shortcoming of this study.

\section{Conclusions}

In TB fields, soil total $\mathrm{N}$, available $\mathrm{P}$ and $\mathrm{S}$, and exchangeable $\mathrm{Ca}$ and $\mathrm{Mg}$ content were significantly lower than in NTB fields, whereas soil pH and OM content were significantly greater. Moreover, $\mathrm{N}$ and $\mathrm{Ca}$ content were below the soil's critical limit value. The decrease in soil N, P, S, Ca, and Mg, despite higher fertilization than the required dose in tobacco fields, indicated that tobacco is a heavy nutrient feeder crop for these nutrients. Farmers are enticed to participate in and continue tobacco production by the possibility of owing family employment, advanced loan, and a buy-back assurance from tobacco companies. Tobacco cultivation deteriorates soil fertility reducing the succeeding crops yield. The government and NGOs working on tobacco control should offer significant monetary help and guaranteeing a superior market facility to sell their other healthier agricultural products.

\section{Declarations}

Data Availability Not applicable

\section{Competing Interests}

The authors do not have any relevant financial or non-financial interests to disclose.

\section{Funding}

The authors state that they did not receive any funding, grants, or other forms of support in the development of this manuscript.

\section{Author Contributions}


All the authors contributed equally in this study. The study's inception and design were aided by all of the writers. Jagadish Chandra Joardar supervised the whole research work. Data collection and analysis were performed by Kaniz Fathema. Sudipa Basu and Jagadish Chandra Joardar did the statistical analysis and interpretation of the results. Sudipa Basu and Jagadish Chandra Joardar wrote the first draft of the manuscript, and all writers provided feedback on prior versions. The final manuscript was read and approved by all authors.

\section{Acknowledgments}

The authors would like to acknowledge the farmers of the study area who helped to conduct the research by proving the valuable information.

\section{References}

1. Ahmed N, Garnett ST (2011) Integrated rice-fish farming in Bangladesh: meeting the challenges of food security. Food Security 3(1):81-92. http://dx.doi.org/10.1007/s12571-011-0113-8

2. Ahmmed S, Jahiruddin M, Razia MS, Begum RA, Biswas JC, Rahman ASMM, Ali MM, Islam KMS, Hossain MM, Gani MN, Hossain GMA, Satter MA (2018) Fertilizer Recommendation Guide-2018. Bangladesh Agricultural Research Council.

3. Ali MY, Islam MF, Rahman MR, Sheema MK, Akhtar MR (2015) Tobacco farming in Bangladesh and its impact on environment. IOSR Journal of Environmental Science, Toxicology and Food Technology 9(12):27-33.

4. Amara DMK, Patil PL, Kamara AM, Saidu DH (2017) Assessment of soil fertility status using nutrient index approach. Academia Journal of Agricultural Research 5(2):28-38.

5. Appau A, Drope J, Witoelar F, Chavez JJ, Lencucha R (2019) Why do farmers grow tobacco? A qualitative exploration of farmers' perspectives in Indonesia and Philippines. Int $\mathrm{J}$ Environ Res Public Health 16(13):2330. http://dx.doi.org/10.3390/ijerph16132330

6. Basu S, Roy A (2018) Economic assessment of mud crab (Scylla Serrata) culture as an adaptation strategy to salinity intrusion in south-west region of Bangladesh. International Journal of Environmental Studies 75(6):891-902. http://dx.doi.org/10.1080/00207233.2018.1470402

7. BBS (Bangladesh Bureau of Statistics) (2016) Statistical Yearbook Bangladesh-2014. Statistics and Information Division (SID), Ministry of Planning, Government of the people's republic of Bangladesh.

8. BBS (Bangladesh Bureau of Statistics) (2020) Statistical Yearbook Bangladesh-2019. Statistics and Information Division (SID), Ministry of Planning, Government of the people's republic of Bangladesh.

9. Bhat ZA, Padder SA, Ganaie AQ, Dar NA, Rehman HU, Wani MY (2017) Correlation of available nutrients with physicochemical properties and nutrient content of grape orchards of Kashmir. $J$ Pharmacogn Phytochem 6(2):181-185.

10. Chase P, Singh OP (2014) Soil nutrients and fertility in three traditional land use systems of Khonoma, Nagaland, India. Resources and Environment 4(4):181-189. 
11. Farooq M, Hussain T, Wakeel $A$, Cheema ZA (2014) Differential response of maize and mungbean to tobacco allelopathy. Expl Agric 50(4):611-624. http://dx.doi.org/10.1017/S0014479714000106

12. Geist $H$ (2018) Soil mining and societal responses: The case of tobacco in Eastern Miombo Highlands. In: Lohnert B, Geist H (eds) Coping with changing environments: social dimensions of endangered ecosystems in the developing world (eBook). Routledge, pp 119-148. https://doi.org/10.4324/9780429463648

13. Haider MZ (2015) Cost-benefit analysis of shrimp cultivation in the south-west region of Bangladesh. International Journal of Environment and Sustainable Development 14(4):315-31. http://dx.doi.org/10.1504/IJESD.2015.072078

14. Hasan KM (2019) Factors influencing farmers turning into tobacco cultivation in the Khulna division of Bangladesh: an empirical study. Tob Prev Cessation Suppl:A128. http://dx.doi.org/10.18332/tpc/105152

15. Höller K, Király L, Künstler A, Müller M, Gullner G, Fattinger M, Zechmann B (2010) Enhanced glutathione metabolism is correlated with sulfur-induced resistance in Tobacco mosaic virusinfected genetically susceptible Nicotiana tabacum plants. Mol Plant Microbe Interact 23(11):14481459.

16. Hoyos CV, Magnitskiy S, Plaza TG (2015) Effect of fertilization on the contents of macronutrients and chlorine in tobacco leaves cv. flue-cured (Nicotiana tabacum L.) in two municipalities in Huila, Colombia. Agron Colomb 33(2):174-183. http://dx.doi.org/10.15446/agron.colomb.v33n2.46839

17. Imamul Huq SM, Didar MA (2005) A Handbook on Analysis of Soil, Plant and Water. BangladeshAustralia Centre for Environmental Research (BACER-DU).

18. Jackson ML. 1958. Soil Chemical Analysis. Prentice-Hall, Inc.

19. Jahan H, Islam MS (2016) Economic performance of live crab (Scylla Serrata) business in the southwest coastal region of Bangladesh. International Journal of Fisheries and Aquatic Studies 4(1):453-457.

20. Kavitha C, Sujatha MP (2015) Evaluation of soil fertility status in various agro ecosystems of Thrissur District, Kerala, India. International Journal of Agriculture and Crop Sciences (IJACS) 8(3):328-338.

21. Khokhar Y, Rattanpal HS, Dhillon WS, Singh G, Gill PS (2012) Soil fertility and nutritional status of Kinnow orchards grown in aridisol of Punjab, India. Afr J Agric Res 7(33):4692-4697.

22. Kutub MJR, Falgunee N (2017) Environmental degradation due to tobacco cultivation in Bangladesh: A case study of Doulathpur, Kushtia. Geografia-Malaysian Journal of Society and Space 11(7):1-8.

23. Lecours N, Almeida GE, Abdallah JM, Novotny TE (2012) Environmental health impacts of tobacco farming: a review of the literature. Tob Control 21(2):191-196.

http://dx.doi.org/10.1136/tobaccocontrol-2011-050318

24. Lisuma J, Mbega E, Ndakidemi $P$ (2020) Influence of tobacco plant on macronutrient levels in sandy soils. Agronomy10(3):418. http://dx.doi.org/10.3390/agronomy10030418 
25. López-Lefebre LR, Rivero RM, García PC, Sanchez E, Ruiz JM, Romero L (2001) Effect of calcium on mineral nutrient uptake and growth of tobacco. Journal of the Science of Food and Agriculture 81(14):1334-1338. http://dx.doi.org/10.1002/jsfa.948

26. Moula MS, Hossain MS, Farazi MM, Ali MH, Mamun MAA (2018) Effects of consecutive two years tobacco cultivation on soil fertility status at Bheramara Upazilla in Kushtia District. J Rice Res 6(1):190. doi: 10.4172/2375-4338.1000190

27. Olsen SR (1954) Estimation of Available Phosphorus in Soils by Extraction with Sodium Bicarbonate (No. 939). U.S. Department of Agriculture.

28. Page AL, Miller RH, Keeney DR (1982) Methods of Soil Analysis, Part 2. Chemical and Microbiological Properties, American Society of Agronomy, Soil Science Society of America.

29. Parker FW, Nelson WL, Winters E, Miles IE (1951) The broad interpretation and application of soil test information. Agron J 43(3):105-112.

30. Pathak H (2010) Trend of fertility status of Indian soils. Current Advances in Agricultural Sciences (An International Journal) 2(1):10-12.

31. Patil RB, Saler RS, Gaikwad VB (2015) Nutritional survey of different vineyards in Nashik district. Maharashtra Journal of Basic Sciences 1:6-12.

32. Patil S, Kumar KA, Srinivasamurthy CA (2017) Soil fertility status and nutrient index for primary nutrients in Western Ghats and Coastal Karnataka under different agro-ecological systems. Asian Journal of Soil Science 12(2):314-319. http://dx.doi.org/10.15740/HAS/AJSS/12.2/314-319

33. Pius ZY (2010) Impact of small scale tobacco growing on the spatial and temporal distribution of Miombo woodlands in Western Tanzania. J Ecol Nat Environ 2(1):10-16.

34. Rahman MS, Ahmed NF, Ali M, Abedin MM, Islam MS (2019) Determinants of tobacco cultivation in Bangladesh. Tob Control 29(6):692-694. http://dx.doi.org/10.1136/tobaccocontrol-2019-055167

35. Rahman MZ, Kabir MH, Alam MM, Islam S (2019) Determinants of tobacco cultivation in Kushtia district, Bangladesh. Int J Agr Ext 7(3):239-246. http://dx.doi.org/10.33687/ijae.007.03.2977

36. Salam MTB, Zaman SS, Hossen ST, Nur MA (2021) Consecutive 2-year data analysis to assess the soil quality and ecological risk of heavy metals in Tobacco field: a case study in Northern Bangladesh. SN Applied Sciences 3(2):1-13. https://doi.org/10.1007/s42452-021-04152-z

37. Shetty YV, Nagamma MS, Kumar MD, Jayaprakash SM (2008) Fertility status in arecanut garden soils of Karnataka. Karnataka Journal of Agricultural Sciences 21(4):503-506.

38. Singh G, Sharma M, Manan J, Singh G (2016) Assessment of soil fertility status under different cropping sequences in District Kapurthala. Journal of Krishi Vigyan 5(1):1-9. http://dx.doi.org/10.5958/2349-4433.2016.00023.4

39. Steel RGD, Torrie JH, Dickey DA (1997) Principles and Procedures of Statistics: a Biometrical Approach. McGraw-Hill.

40. Walkey A, Black TA (1934) An examination of the Dugtijaraff method for determining soil organic matter and proposed modification of the chronic and titration method. Soil Sci 37(1):23-38. 
41. WHO (World Health Organization) (2017) Tobacco and its environmental impact: an overview. World Health Organization.

42. Xu ZC, Wang L, Xiao HQ (2008) pH distribution and relationship to soil nutrient in Hunan tobacco lands. Chinese Journal of Eco-Agriculture 16(4):830-834.

http://dx.doi.org/10.3724/SP.J.1011.2008.00830 